(1]

'EBAP and CME Senior Coordinator, Lausanne, Switzerland.

2Pulmonary Care Division, University Hospital Basel, Basel, Switzerland.

${ }^{3}$ Dept of Respiratory Medicine, Maastricht University Medical Center,

Maastricht, the Netherlands.

\title{
ERS/EBAP European Accreditation of Training Centres in Adult Respiratory Medicine: how could it benefit your centre?
}

In June 2014, the European Respiratory Society (ERS) launched an accreditation programme for training centres in adult respiratory medicine in Europe, in partnership with the European Board for Accreditation in Pneumology (EBAP). The European Accreditation of Training Centres in Adult Respiratory Medicine forms part of the overall objective for harmonised education in respiratory medicine for European specialists (HERMES).

EBAP is the European specialty accreditation board responsible for assessing the quality and independence of continuing medical education (CME) and continuing professional development (CPD) activities in the field of respiratory medicine. It has been appointed to lead the training centre accreditation process in collaboration with the ERS. EBAP also works closely together with the Forum of European Respiratory Societies (FERS) and with the European Union of Medical Specialists (UEMS).

\section{How do training centres qualify?}

As this is a voluntary process, all training centres in adult respiratory medicine can apply for accreditation if they have already received accreditation from their national or local accreditation body.
The process is based on an extensive list of criteria outlined in an article published in Breathe in 2010, entitled "Adult HERMES: criteria for accreditation of ERS European training centres in adult respiratory medicine" [1]. The criteria have been divided in two categories:

1 Basic standards: the basic standards must be met and fulfilment must be demonstrated during the evaluation of the training programme, including at the site visit stage.

2 Standards for quality development: these standards are in accordance with international consensus regarding best practice for postgraduate medical education. Fulfilment of, or initiatives to fulfil, such standards should be documented.

The European Accreditation of Training Centres in Adult Respiratory Medicine programme was designed to be inclusive of smaller centres and smaller European countries. As such, a training centre can be composed of either a single participating training centre or, alternatively, a number of training sites building a network. Criteria outlined within the article previously published in Breathe [1] may be met by a number of participating training centres forming a training centre network, provided that there is a formal and documented collaboration agreement between the participating sites.
Cite as: Sutter S, Stolz D, Rohde G, et al. ERS/EBAP European Accreditation of Training Centres in Adult Respiratory Medicine: how could it benefit your centre? Breathe 2015; 11: 183-185

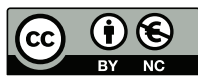
ERS 2015 


\section{How will accreditation benefit my training centre?}

Training centres taking part in the programme are given a unique opportunity to benchmark against European standards.

After a year of his centre being accredited, Sebastian Thiel from HELIOS Lungenklinik Heckeshorn in Berlin, Germany (figure 1), reported to the ERS/EBAP Accreditation Committee that:

"Accreditation as a training centre in the short term had a positive impact for our centre by providing the impulse to review our processes and the structure of our training. It was also an occasion for trainees to contribute with their own ideas on clinical education [...] In the long term, we expect an improvement in our education and offering our trainees the opportunity of an exchange with trainees from other countries. We also expect our centre to be even more interesting for trainees from other countries because of the harmonisation of curricula."

A respiratory medicine trainee interviewed at the Semmelweis University Medical Centre

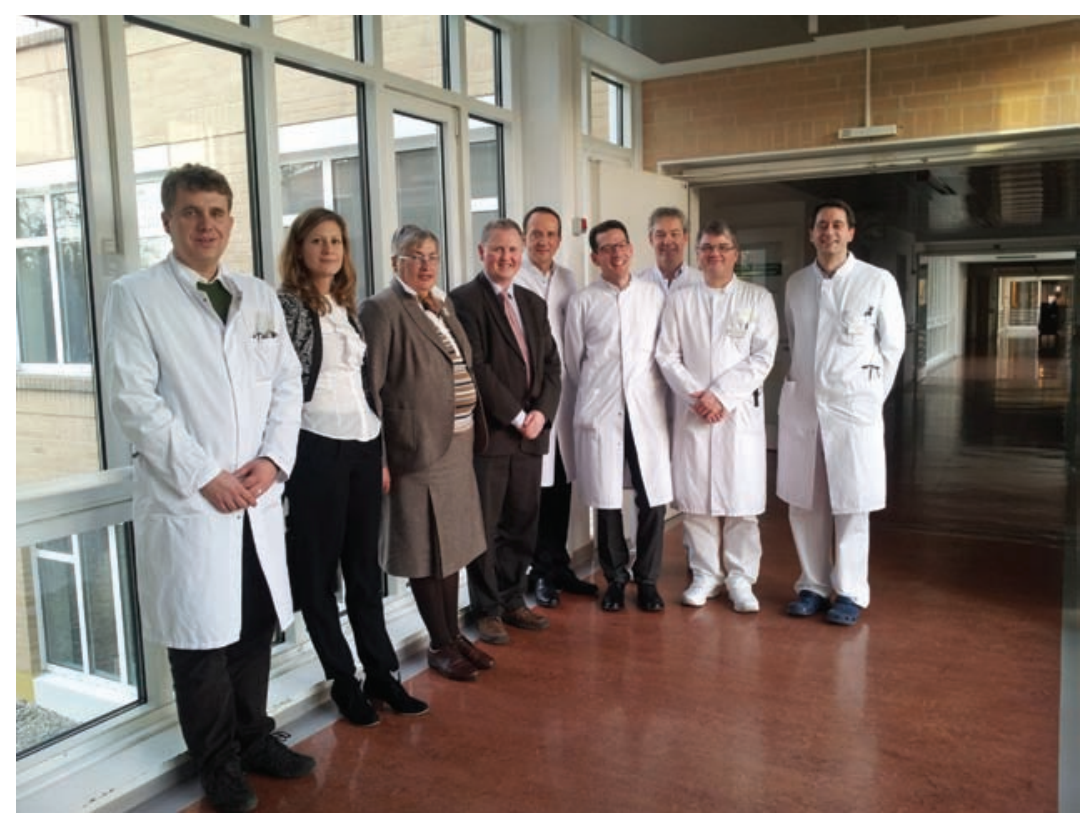

Figure 1 Site visit at the HELIOS Lungenklinik Heckeshorn in Berlin, Germany, December 2013.
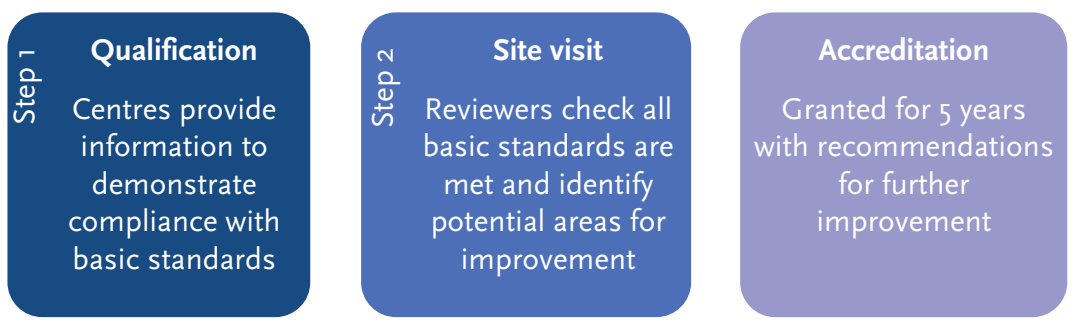

Figure 2 The accreditation process. in Budapest, Hungary, told the ERS/EBAP review team:

"With the recent development of respiratory medicine (new drugs, noninvasive ventilation, lung transplantation, etc.) and the growing number of patients, it is essential to define our responsibilities and harmonise education among different countries."

Another major benefit of the whole process is that key aspects of training, including teaching and assessment methods and trainee supervision are audited by an independent entity. Training centres are provided with guidance by the review team who will suggest improvements when necessary, regardless of whether the training centre passes or fails the accreditation. This external, independent assessment might facilitate consideration of the current needs of the training centre in discussion with the hospital or university leadership.

In addition, accredited training centres can transparently document their quality standards in order to become eligible for European educational and clinical projects.

\section{What is the accreditation process?}

The process is divided into two steps (figure 2):

\section{Step 1: qualification}

The aim of this first step is primarily to determine whether the applying training centre or training centre network qualifies for a site visit, and to provide preliminary recommendations for quality improvement.

The applying training centre or training centre network is required to complete an extensive application form, which includes basic questions on the participating site or sites, regarding the programme director, the clinical and educational supervisors, the teaching faculty and the trainees. Most importantly, the application contains a set of questions specifically related to each of the criteria outlined in the previously published Breathe article [1].

The training centre must also collect the curricula vitae of the programme director, the clinical and/ or educational supervisors and the trainers, and is required to provide the clinical and educational programmes as well as the trainees' rotation plan.

Collating this data can be time consuming and it is recommended that one person is assigned to complete the application and collect the requested information and documents. If possible, this person should be the primary contact at the training centre throughout the entire process.

Once received by the EBAP office, the completed application is thoroughly examined, first by EBAP staff to ensure the information provided 
is complete, then by a team of reviewers that is composed of:

- one reviewer appointed by the ERS;

- one reviewer appointed by EBAP; and

- a third national reviewer who, depending on the centre's location, will either be a representative appointed by the national accreditation authority, or by the national society or by the UEMS.

It is the review team's responsibility is to assess whether the training centre or network qualifies and is ready for a site visit. If so, a recommendation to that effect is put forward by the Accreditation Committee so that the second phase of the process can be initiated.

At the end of Step 1, all training centres receive a report based on the information they have provided.

\section{Step 2: site visit}

Dates for the site visit are agreed between the training centre and the review team, long enough after completion of step 1 to allow sufficient preparation time. Before the site visit takes place, the training centre or network is required to provide an additional set of documents, preferably in English, including in- and outpatient statistics, audit reports, examples of logbooks/portfolios and internal evaluation forms.

The site visit generally lasts 1-2 days depending on the size of the training centre. In the case of a training centre network application and depending on the number and location of participating sites, the visit may be extended. Individual interviews are conducted with the programme director, clinical and/or educational supervisor(s), teaching faculty, and five or six trainees selected by the review team. The EBAP office provides guidance to the training centre for adequate preparation of the schedule and site visit. Onsite, the review team will request access to the training centre standards, guidelines and protocols, incident reports and, whenever available, the latest annual reports.

At the end of the site visit, the review team will already provide a preliminary assessment as well as recommendations for improvement. This will be formalised in the form of a written report to the training centre after the site visit.

Based on the recommendations by the review team, the Accreditation Committee will decide

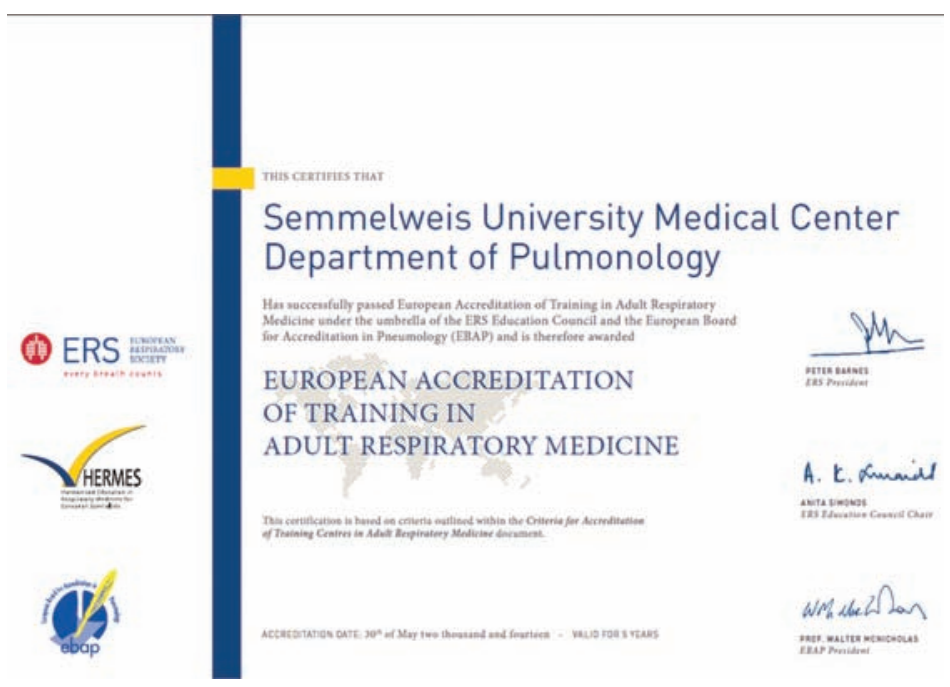

Figure 3 Accreditation of Training Centre Certificate.

whether the training centre or training centre network can be granted accreditation (figure 3). The accreditation is valid for 5 years and can be renewed upon request by the training centre or training centre network. The accreditation renewal and renewal process will depend on the outcome of the first site visit and whether the training centre or training centre network can demonstrate that the recommendations made have been taken into account.

\section{How can my centre apply?}

Information about to the criteria, process and fees is available on the EBAP and HERMES websites. Your training centre can request the application and related supporting documents by completing the statement of interest form available on:

- the EBAP website (http://www.ebap.org/ accreditation/training-centres); and

- the HERMES website (http://hermes.ersnet. org/accreditation/application).

The completed document must be sent to EBAP headquarters at ebap.info@ebap.org. If you have any questions about the European Accreditation of Training Centres in Adult Respiratory Medicine process or criteria, do not hesitate to contact EBAP office at ebap.info@ebap.org.

\section{Conflict of interest}

Disclosures can be found alongside the online version of this article at breathe.ersjournals.com. S. Sutter is an employee of the European Respiratory Society (ERS) and the European Board for Accreditation in Pnemology (EBAP).

\section{References}

1. Loddenkemper R, Séverin T, Mitchell S, et al. Adult HERMES: criteria for accreditation of ERS European training centres in adult respiratory medicine. Breathe 2010; 7: 170-176. 